\title{
Composição e variação sazonal da riqueza do fitoplâncton na foz de rios do delta do Jacuí, RS, Brasil ${ }^{1}$
}

\author{
S.C. Rodrigues ${ }^{2}$, Lezilda Torgan ${ }^{3,5}$ e Albano Schwarzbold ${ }^{4}$
}

Recebido em 23/01/2006. Aceito em 25/01/2007

\begin{abstract}
RESUMO - (Composição e variação sazonal da riqueza do fitoplâncton na foz de rios do delta do Jacuí, RS, Brasil). Este estudo teve como objetivo descrever e comparar a composição e riqueza do fitoplâncton na foz dos rios Gravataí, Sinos, Caí e Jacuí, durante as quatro estações do ano. A investigação baseou-se em amostragens realizadas bimestralmente na subsuperfície da água, no período de dezembro/ 2000 a dezembro/2001. A comunidade fitoplanctônica, na foz dos quatro rios, esteve composta por 470 espécies (incluindo as não determinadas), 135 gêneros e nove classes taxonômicas. Chlorophyceae e Bacillariophyceae foram as classes mais representativas em número de espécies. A alta riqueza está, provavelmente, associada à ocorrência de reservatórios e banhados no curso superior destes rios e à presença de áreas úmidas na planície de inundação do delta do Jacuí. A temperatura e o nível fluviométrico foram os principais fatores determinantes da variação sazonal da composição e riqueza da comunidade fitoplanctônica.
\end{abstract}

Palavras-chave: fitoplâncton, riqueza, variação sazonal, sistema lótico

\begin{abstract}
Composition and seasonal richness variation of phytoplankton at river mouths of the Jacuí Delta, Rio Grande do Sul State, Brazil). This study describes and compares phytoplankton composition and richness at the mouths of the Gravataí, Sinos, Caí, and Jacuí rivers during the four seasons of the year. The investigation was based on bimonthly sampling of subsurface water, from December/2000 to December/2001. The phytoplankton community of the four river mouths was composed by 470 species (including those unidentified), 135 genera, and nine taxonomic classes. Chlorophyceae and Bacillariophyceae were the most representative classes in species number. High richness was probably associated with the presence of dams and swamps on the upper course of these rivers, and also with the wetlands of the Jacuí Delta floodplains. Temperature and fluviometric level were the main factors determining seasonal composition and richness variation of the phytoplankton community.
\end{abstract}

Key words: phytoplankton, richness, seasonal variation, lotic system

\section{Introdução}

Historicamente, o fitoplâncton de ambientes lóticos tem recebido menos atenção em estudos limnológicos. Rios fornecem hábitats que estão sujeitos a constantes mudanças e, nestes ambientes, a manutenção e o desenvolvimento da comunidade fitoplanctônica pode ocorrer, porém raramente são mantidos por um longo período, pois são transportados continuamente à jusante. Apenas em rios calmos ou, na foz dos formadores de delta, pode-se desenvolver o potamoplâncton (Round 1983). O estudo das populações fitoplanctônicas em ambientes lóticos no Brasil é, portanto, escasso (Bicudo et al. 1992; Rolla et al. 1992; Bittencourt-Oliveira \& Castro 1993; Bittencourt-Oliveira 1993a; 1993b; 1997; 2002;
Bittencourt-Oliveira \& Mecenas 1994; Oliveira \& Calijuri 1995; Train \& Rodrigues 1997; 1998; Musarra et al. 1998; Santos \& Rocha 1998; Souza 1998; Câmara et al. 2002; Borges et al. 2003) tendo início no século dezenove nos rios tropicais da bacia do Amazonas (Dickie 1881; Möbius 1892; Thomasson 1971; Schmidt \& Uherkovich 1973; Uherkovich 1976; 1981; Uherkovich \& Rai 1979). O conhecimento da biodiversidade em ambientes lóticos, acompanhado das condições físicas e químicas da água, torna-se cada vez mais necessário como base para o monitoramento da qualidade da água, pois são sistemas que vêm sendo afetados por um crescente impacto antrópico.

$\mathrm{O}$ presente estudo aborda o fitoplâncton de rios formadores do delta do Jacuí (Gravataí, Sinos, Caí e Jacuí), os quais em seu curso inferior, por percorrerem

\footnotetext{
1 Parte da Dissertação de Mestrado do primeiro Autor

2 Universidade Federal do Rio Grande do Sul, Programa de Pós-Graduação em Ecologia, Porto Alegre, RS, Brasil

3 Fundação Zoobotânica do Rio Grande do Sul, Secção de Criptógamas, Museu de Ciências Naturais, Rua Dr. Salvador França 1427, Jardim Botânico, 90690-000 Porto Alegre, RS, Brasil

4 Universidade Federal do Rio Grande do Sul, Instituto de Biociências, Departamento de Ecologia, Av. Bento Gonçalves 9500, Prédio 43422, 91501-970 Porto Alegre, RS, Brasil (albano@ecologia.ufrgs.br)

5 Autor para correspondência: torgan@cpovo.net
} 
grande extensão em terrenos pouco acidentados, tornam-se ambientes favoráveis ao desenvolvimento da comunidade fitoplanctônica.

Análises do fitoplâncton nestes rios tiveram início em 1970, com o monitoramento efetuado pelo Departamento Municipal de Águas e Esgotos de Porto Alegre (DMAE), cujos dados são encontrados em vários relatórios, contendo listas de gêneros e, para as diatomáceas, em algumas ocasiões, foi efetuada identificação de espécies. Também, foram realizados estudos taxonômicos de grupos específicos do fitoplâncton por Martau et al. (1977), para as diatomáceas do Rio dos Sinos e, por Alves-da-Silva \& Avila (1997), para as Euglenaceae pigmentadas do Parque Estadual Delta do Jacuí. Os primeiros trabalhos que abordaram a composição específica do fitoplâncton são os de Torgan et al. (1979), com o registro de 55 espécies para o rio Caí, no período de outubro de 1977 a janeiro de 1978, no trecho de influência do III Pólo Petroquímico e o de Rosa et al. (1988), mencionando um total de 130 espécies, no ano de 1986, para o rio Jacuí.

Em 1998, com o Programa para o Desenvolvimento Racional, Recuperação e Gerenciamento Ambiental da Bacia Hidrográfica do lago Guaíba (Pró-Guaíba), deu-se início às amostragens e ao primeiro diagnóstico da ficoflora e das condições físicas, químicas e microbiológicas da água na foz dos rios do delta do Jacuí (Torgan et al. comunicação verbal). E, com base nestas amostragens, Fortes et al. (2003) realizaram um estudo taxonômico sobre os organismos pertencentes à ordem Chlorococcales, no rio dos Sinos, abordando 32 espécies.

Este trabalho teve como objetivo efetuar uma análise comparativa da composição e da riqueza do fitoplâncton na foz dos rios Gravataí, Sinos, Caí e Jacuí, verificando sua variação durante as quatro estações do ano, com a finalidade de contribuir para o conhecimento da diversidade e dinâmica da comunidade fitoplanctônica de um sistema lótico, na região subtropical brasileira.

\section{Material e métodos}

A área de estudo está localizada no delta do Jacuí (coordenadas geográficas $29^{\circ} 53^{\prime}$ e $30^{\circ} 03^{\prime} \mathrm{S}$ e $51^{\circ} 28^{\prime}$ e $\left.51^{\circ} 13^{\prime} \mathrm{W}\right)$, planície de inundação formada pela confluência dos rios Gravataí, Sinos, Caí e Jacuí. As amostragens do fitoplâncton foram realizadas bimestralmente, em estações georeferenciadas localizadas a cerca de 2 a $5 \mathrm{~km}$ da foz dos rios Gravataí (482946 UTM 6684785), Sinos (476839 UTM 6690371), Caí (471878 UTM 6689028) e Jacuí (465478 UTM 6685328), no período de dezembro/ 2000 a dezembro/2001. Medidas de temperatura, condutividade elétrica (condutivímetro YSI mod. 30), pH (pHmetro de campo Hach mod. EC10) e transparência Secchi da água foram obtidas no próprio local da coleta. As análises químicas (alcalinidade, oxigênio dissolvido, $\mathrm{DBO}_{5}$, fosfato-total, nitrogênio amoniacal, nitrato, nitrito, sílica e matéria orgânica) e bacteriológicas (coliformes fecais e totais) foram efetuadas de acordo com as técnicas descritas em APHA (1992). Os dados de nível fluviométrico, obtidos em locais próximos às estações de amostragem, foram fornecidos pela Companhia de Pesquisa de Recursos Minerais (CPRM). As amostras para análise do fitoplâncton foram coletadas com frascos na subsuperfície da água $(\cong 20 \mathrm{~cm})$ e fixadas com solução de lugol neutro (Sournia 1978). Para confirmação de alguns táxons, principalmente de fitoflagelados, utilizou-se amostras de rede (abertura de malha $25 \mu \mathrm{m}$ ), fixadas com formol a $4 \%$ $\mathrm{e}$, amostras in vivo, com a finalidade de observar estruturas como flagelos, plastídeos, pirenóides, etc. Para a identificação das diatomáceas, o material foi oxidado com peróxido de hidrogênio e dicromato de potássio, sendo confeccionadas lâminas permanentes utilizando-se a resina Naphrax (I.R.=1,74) como meio de inclusão. O material encontra-se tombado no Herbário Prof. Dr. Alarich Schultz (HAS) da Fundação Zoobotânica do Rio Grande do Sul, sob os números HAS 35511-35538; 35545-35578; 3571135726; 103263-103266 e 103484-103495. Subamostras de $10 \mathrm{~mL}$ foram observadas em câmaras de sedimentação, em microscópio invertido e/ou posteriormente entre lâmina e lamínula, em microscópio equipado com contraste de fase. O enquadramento dos táxons em nível de classe foi baseado em Hoeck et al. (1995). Para estabelecer as relações entre a variação sazonal da riqueza fitoplanctônica e as variáveis ambientais foi utilizada a Análise de Correspondência Canônica (ACC). A ACC foi processada no programa PC-ORD $(4.0)^{\circledR}$ a partir dos dados de riqueza de espécies das classes fitoplanctônicas $(n=240)$ e das variáveis ambientais ( $\mathrm{n}=168)$ : temperatura (temp), nível fluviométrico (fluv), fosfato-total $\left(\mathrm{PO}_{4}\right)$, nitrogênio amoniacal $\left(\mathrm{N}-\mathrm{NH}_{3}\right)$, nitrato $\left(\mathrm{NO}_{3}\right)$, nitrito $\left(\mathrm{NO}_{2}\right)$ e sílica (silic), referentes às 24 unidades amostrais. 


\section{Resultados}

Composição do fitoplâncton - A comunidade fitoplanctônica, na foz dos rios Gravataí, Sinos, Caí e Jacuí, esteve composta por um total de 470 espécies (incluindo as indeterminadas), 135 gêneros e nove classes taxonômicas (Bacillariophyceae, Chlorophyceae, Chrysophyceae, Cryptophyceae, Cyanophyceae, Dinophyceae, Euglenophyceae, Xanthophyceae e Zygnematophyceae). As classes mais representativas em todos os rios foram Chlorophyceae com 158 espécies $(33,4 \%)$, seguida de Bacillariophyceae com 114 espécies $(24,1 \%)$ e de Euglenophyceae com 83 espécies (17,5\%) (Tab. 1). O número de espécies comuns a estes rios foi baixo (60 spp.), enquanto que o número de espécies exclusivas foi mais expressivo (255 spp.), ou seja, 54,2\% do total (Tab. 1). Espécies encontradas exclusivamente no rio Gravataí, foram mais numerosas (73 spp.), pertencentes principalmente às classes Euglenophyceae e Chlorophyceae. Nos rios Jacuí e dos Sinos encontrou-se 68 e 63 espécies exclusivas, respectivamente, pertencentes principalmente às classes Chlorophyceae e Bacillariophyceae, no rio Jacuí e às Euglenophyceae e Bacillariophyceae, no rio dos Sinos. O rio Caí apresentou o menor número de espécies exclusivas (51 spp.), predominantemente pertencentes à classe Chlorophyceae (Tab. 2).

A contribuição relativa, em número de espécies de cada classe demonstrou, em geral, um padrão semelhante entre os rios, com exceção de Euglenophyceae, que apresentou maior porcentagem nos rios dos Sinos e Gravataí (Fig. 1). A composição do fitoplâncton, entretanto, foi relativamente distinta entre os rios. Os gêneros Desmodesmus e Scenedesmus se destacaram em número de espécies nos quatro rios. Outros, como Euglena e Trachelomonas, estiveram melhor representados nos rios Gravataí e Sinos, asssim como Cryptomonas e Monoraphidium nos rios Caí, Gravataí e Jacuí, enquanto que Nitszchia se destacou nos rios Gravataí e Jacuí. Nas Fig. 2-23 estão ilustradas algumas espécies identificadas, incluindo representantes dos gêneros citados.

Variação sazonal - A composição do fitoplâncton, no ano de estudo, demonstrou uma nítida variação sazonal (Fig. 24). A classe Chlorophyceae predominou em número de táxons nos quatro rios, no verão de 2000 e outono de 2001, sendo substituída no final de outono e inverno pelas Bacillariophyceae, nos rios Sinos, Gravataí e Jacuí. Na primavera, as Chlorophyceae voltaram a ter maior representatividade em número de táxons, compartilhando principalmente com as Bacillariophyceae e Euglenophyceae nos rios Gravataí e Sinos e, com as Bacillariophyceae e Cryptophyceae nos rios Caí e Jacuí.

A riqueza específica apresentou variação semelhante nos rios dos Sinos e Caí, iniciando no verão de $2000 \mathrm{com}$ valores altos (média de $62 \mathrm{spp}$.), decrescendo no final do outono (<50 spp.) e retomando o crescimento nas estações de inverno e primavera de 2001. No rio Gravataí, a riqueza manteve-se com valores baixos desde o verão até o final do outono (<50 spp.) vindo a aumentar também a partir da estação de inverno. A riqueza no rio Jacuí apresentou

Tabela 1. Número de espécies das diferentes classes fitoplanctônicas, comuns e exclusivas, dos rios formadores do delta do Jacuí, RS, Brasil, no período de dezembro/2000 a dezembro/2001.

\begin{tabular}{|c|c|c|c|c|c|c|}
\hline \multirow[b]{2}{*}{ Classes } & \multicolumn{6}{|c|}{$\mathrm{N}^{\mathrm{o}}$ de espécies } \\
\hline & Rio Gravataí & Rio dos Sinos & Rio Caí & Rio Jacuí & Total geral & spp. comunsaos rios \\
\hline BACILLARIOPHYCEAE & 59 & 59 & 44 & 48 & 114 & 13 \\
\hline CHLOROPHYCEAE & 75 & 70 & 87 & 79 & 157 & 30 \\
\hline CHRYSOPHYCEAE & 11 & 13 & 5 & 8 & 19 & 2 \\
\hline CRYPTOPHYCEAE & 11 & 11 & 13 & 16 & 19 & 7 \\
\hline CYANOPHYCEAE & 13 & 18 & 11 & 18 & 29 & 5 \\
\hline DINOPHYCEAE & 2 & 5 & 5 & 7 & 12 & 1 \\
\hline EUGLENOPHYCEAE & 42 & 41 & 21 & 13 & 83 & 2 \\
\hline XANTHOPHYCEAE & 2 & 1 & 0 & 2 & 3 & 0 \\
\hline ZYGNEMATOPHYCEAE & 6 & 9 & 10 & 5 & 20 & 0 \\
\hline NÃO IDENTIFICADA & 8 & 4 & 3 & 3 & 14 & 0 \\
\hline Total & 229 & 231 & 199 & 199 & 470 & 60 \\
\hline spp. exclusivas & 73 & 63 & 51 & 68 & 255 & - \\
\hline
\end{tabular}


Rodrigues, Torgan \& Schwarzbold: Composição e variação sazonal da riqueza do fitoplâncton na foz de rios...

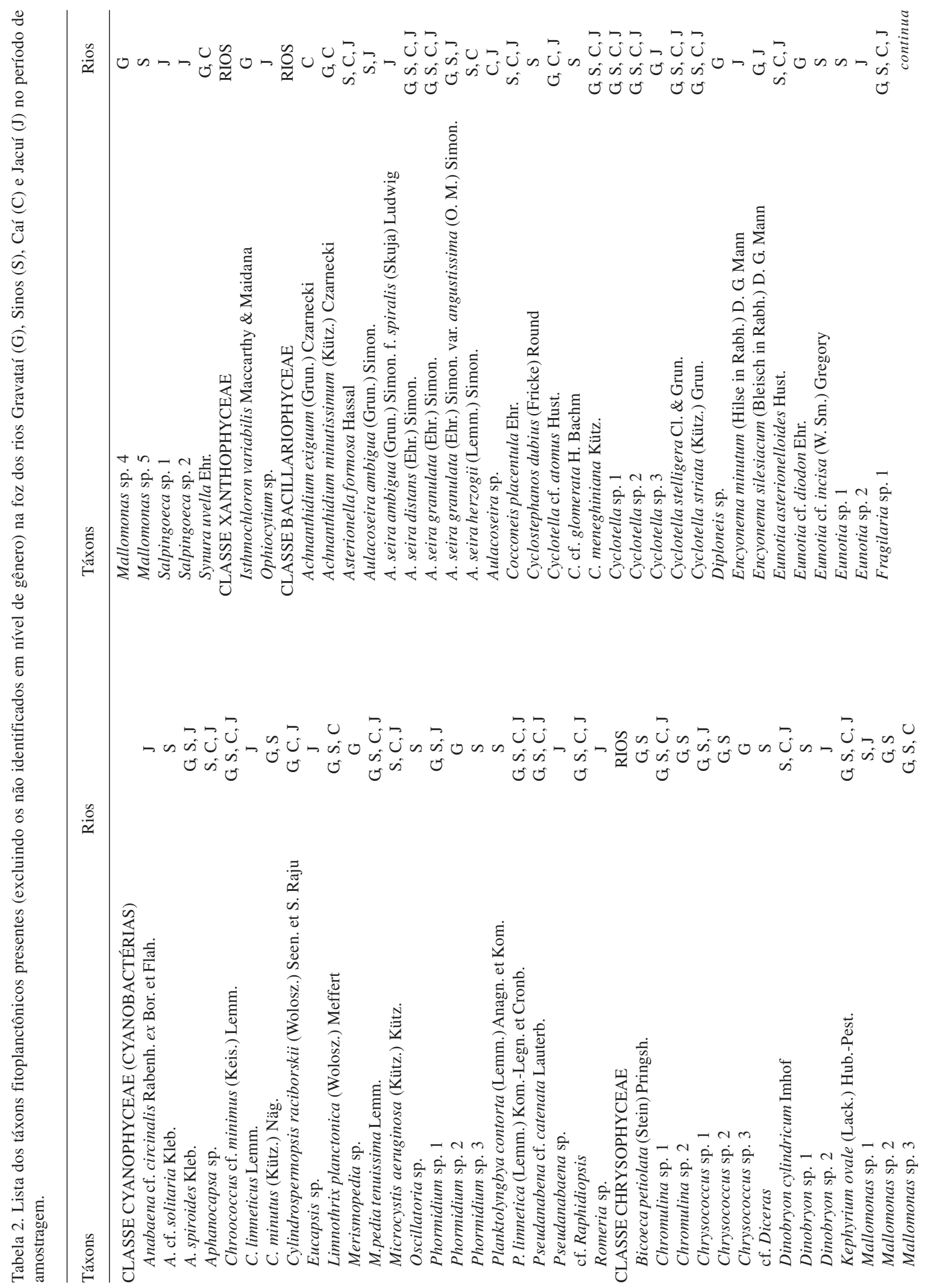




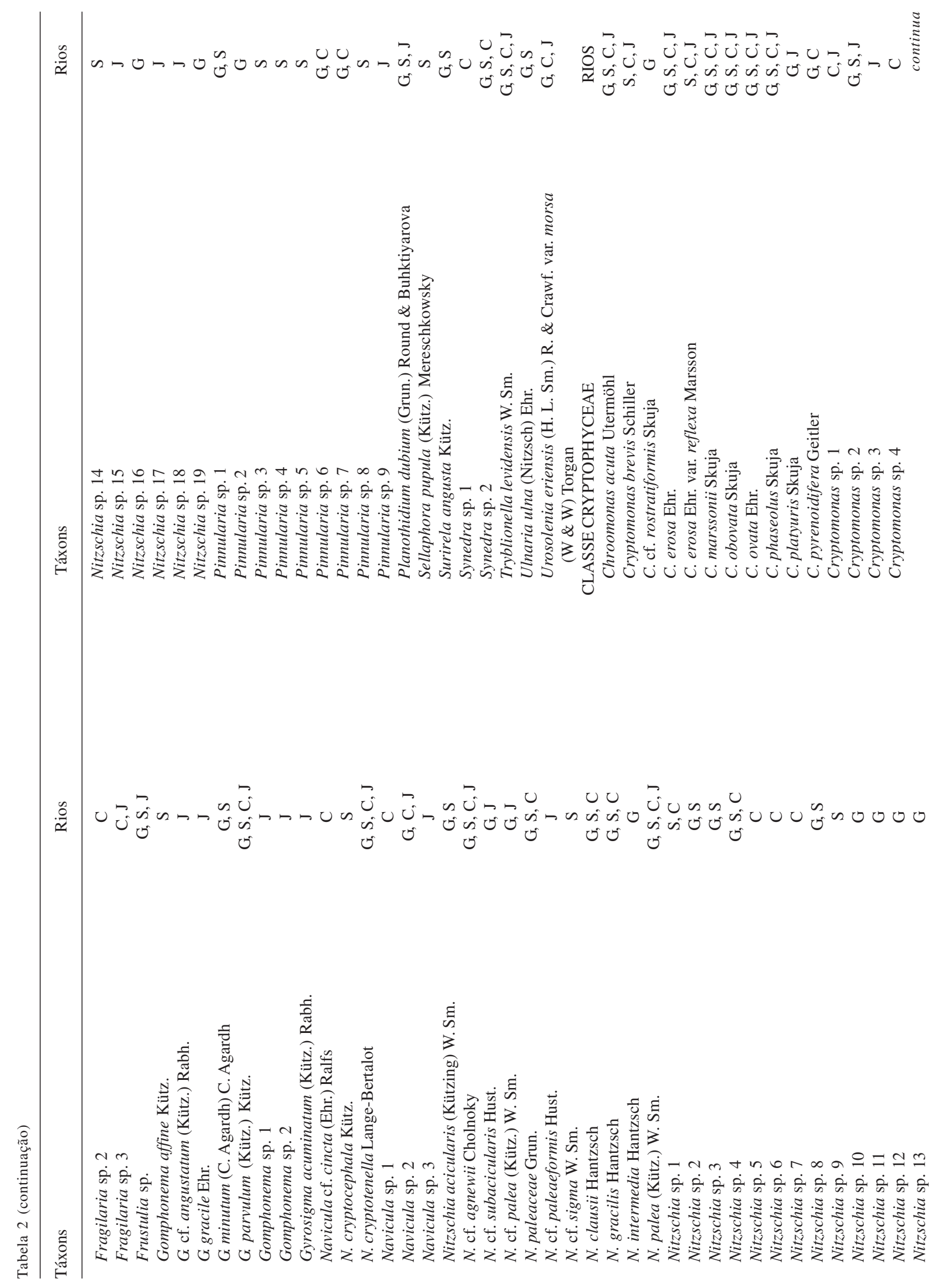




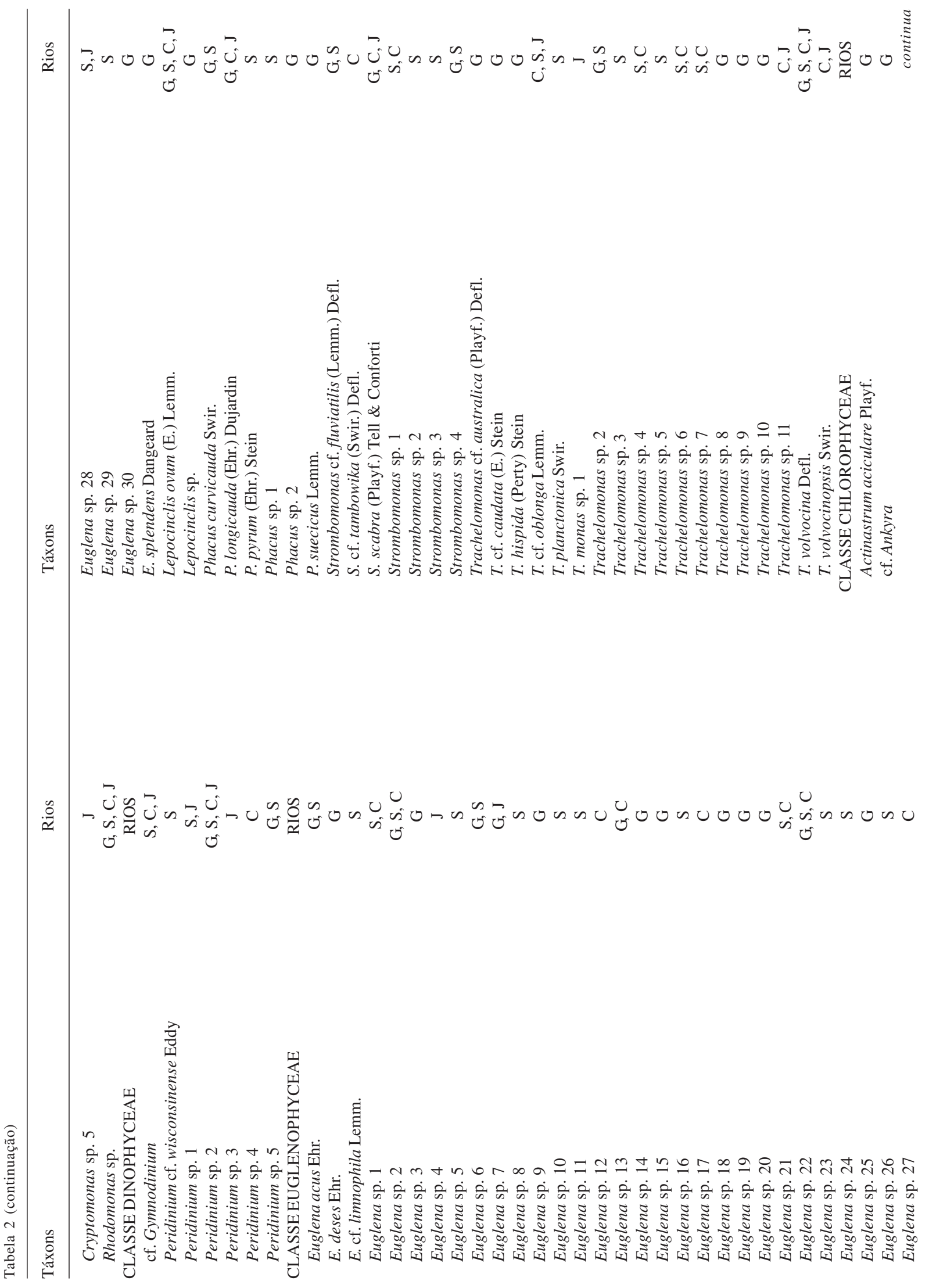




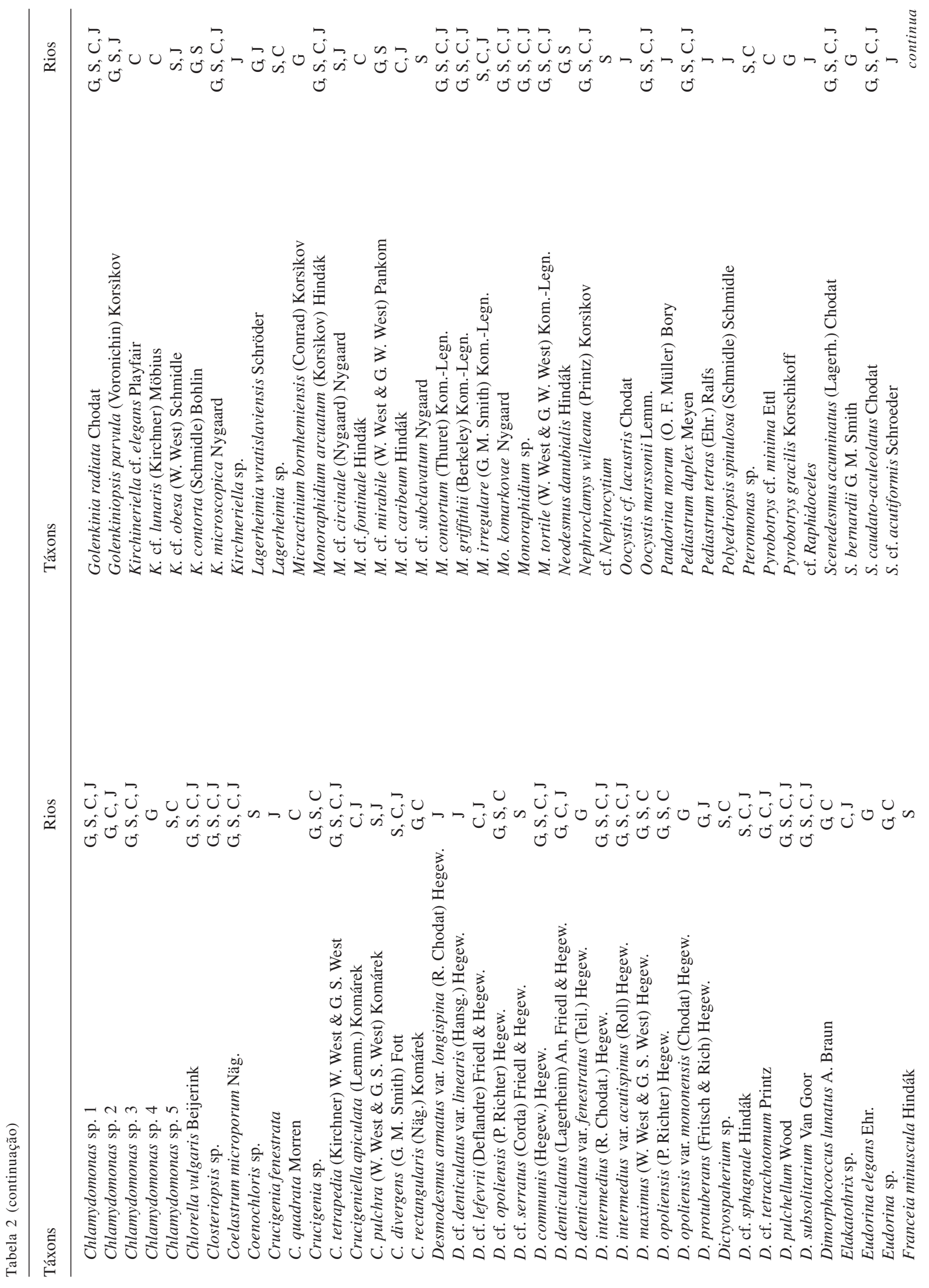




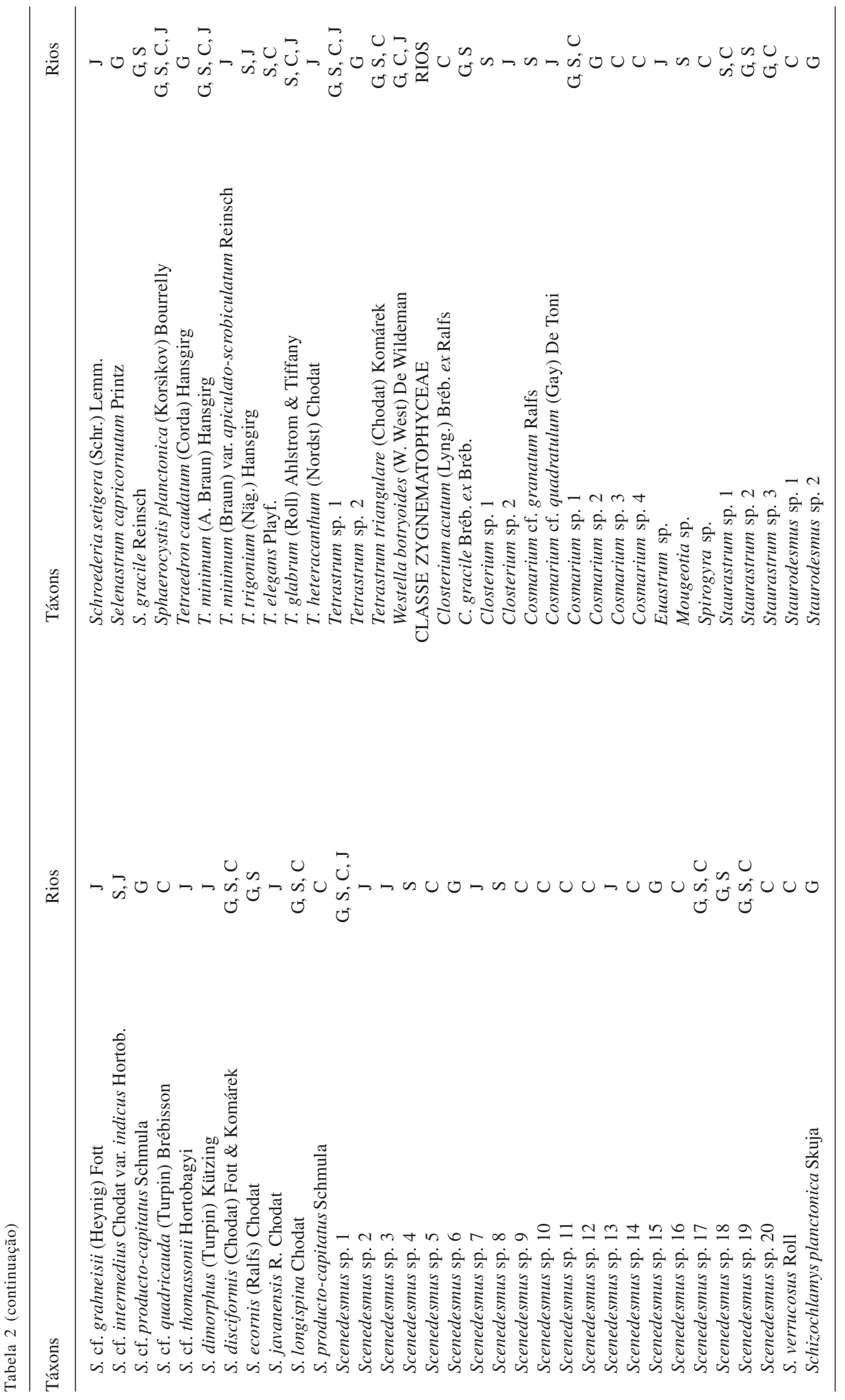


Rio Gravataí

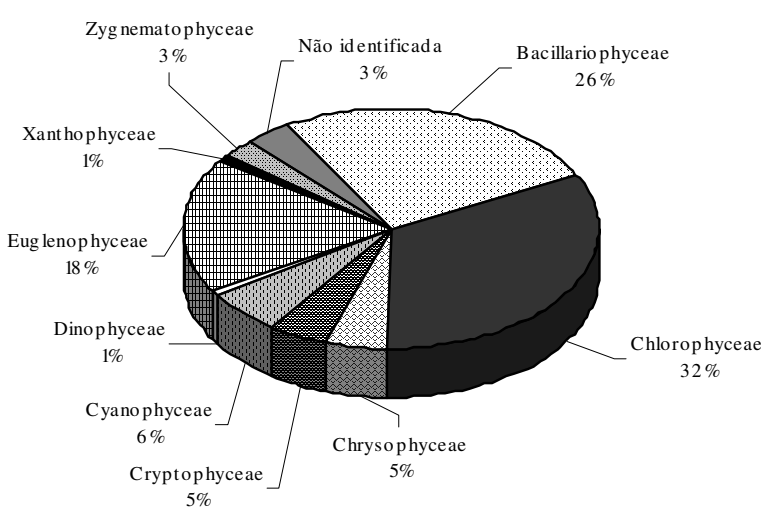

Rio Caí

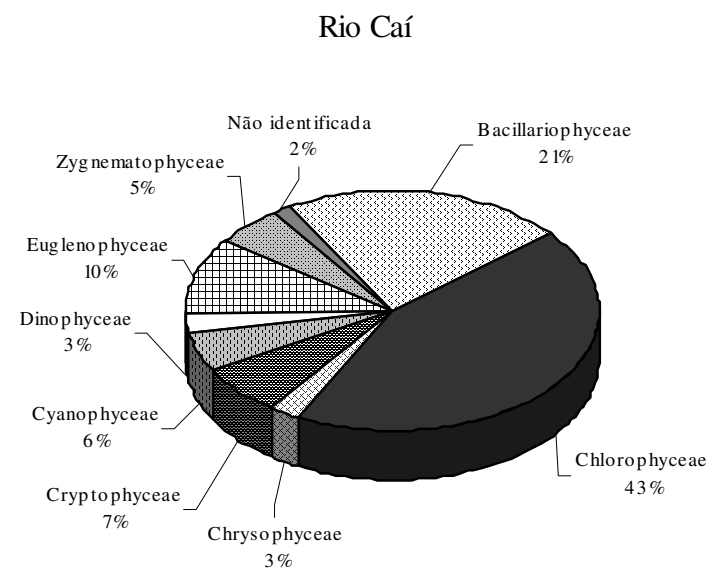

C
A

Rio dos Sinos

B

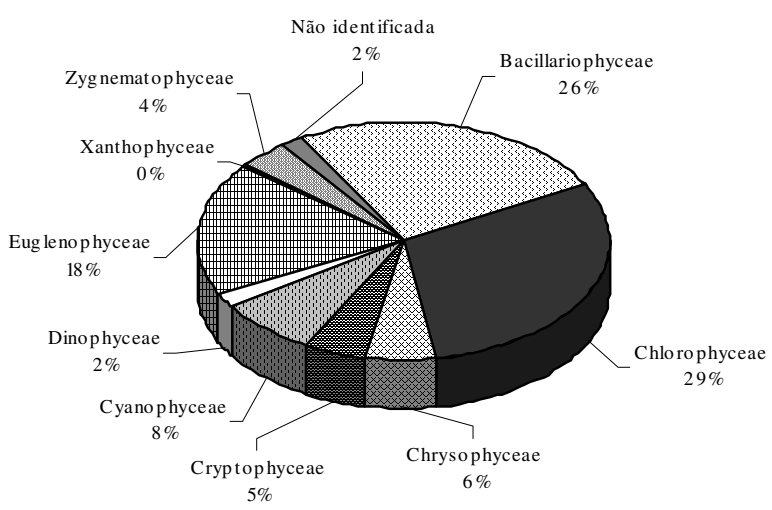

Jacuí (D), RS, Brasil, no período de dezembro/2000 a dezembro/2001.

maior variação, iniciando com valores altos no verão (> 70 spp.) decrescendo na estação de outono, elevando-se no inverno e, vindo a decrescer novamente, na primavera de 2001 (Fig. 25).

Características físicas, químicas e bacteriológicas da água - As águas na foz dos rios no delta do Jacuí apresentaram-se levemente ácidas (pH médio de 6,7) e com baixa transparência $(<0,50 \mathrm{~m})$. Pode-se observar que os rios Gravataí e Sinos apresentaram valores mais altos de condutividade elétrica $\left(>50 \mathrm{mS} . \mathrm{cm}^{-1}\right)$, matéria orgânica $\left(>4,3 \mathrm{mg} \mathrm{L}^{-1}\right), \mathrm{DBO}_{5}\left(>1,3 \mathrm{mg} \mathrm{L}^{-1}\right)$, fosfatototal $\left(>0,11 \mathrm{mg} \mathrm{L}^{-1}\right)$ e coliformes totais e fecais (médias $>50.000$ NMPorg. $100 \mathrm{~mL}^{-1}$ ) e, valores mais baixos de OD $\left(<6,1 \mathrm{mg} \mathrm{L}^{-1}\right)$, em relação aos rios Caí e Jacuí (Tab. 3).

Relação entre a riqueza fitoplanctônica e as variáveis ambientais - A relação das variáveis abióticas: temperatura (temp), nível fluviométrico (fluv), fosfatototal $\left(\mathrm{PO}_{4}\right)$, nitrogênio amoniacal $\left(\mathrm{N}-\mathrm{NH}_{3}\right)$, nitrato $\left(\mathrm{NO}_{3}\right)$, nitrito $\left(\mathrm{NO}_{2}\right)$ e sílica (silic) (Tab. 3) com a riqueza da comunidade fitoplanctônica na foz dos rios do delta do Jacuí é demonstrada pelas correlações de Pearson e probabilidades (teste de Monte Carlo) obtidas através da análise de correspondência canônica. $\mathrm{O}$ resultado da ACC (Fig. 26), com 36,5\% de explicação da variabilidade total dos dados, nos eixos I e II, demonstrou que, dentre as variáveis analisadas, a temperatura $(\mathrm{r}=0,794)$ e o nível fluviométrico $(\mathrm{r}=-0,539)$, apresentaram correlações significativas $(p<0,01)$ com a riqueza específica do fitoplâncton dos rios.

\section{Discussão}

Com base nos resultados deste estudo, foi possível verificar que a comunidade fitoplanctônica na foz dos 


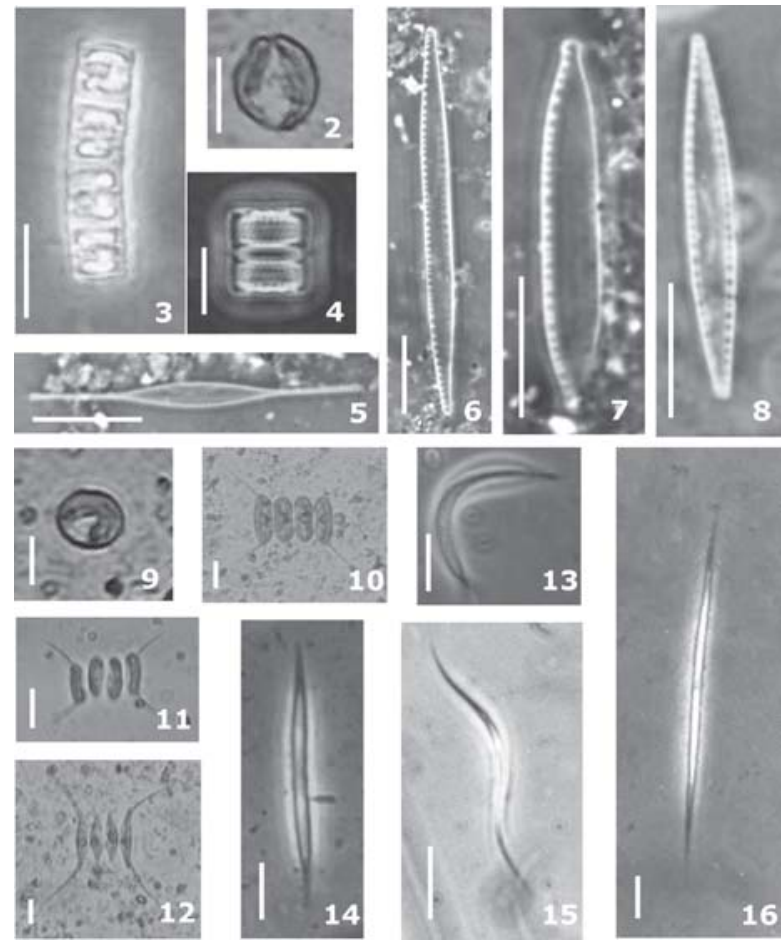

Figuras 2-16. 2. Chromulina sp. 1. 3-4. Aulacoseira distans (Ehr.) Simon. 5. Nitzschia cf. agnewii Choln. 6. Nitzschia gracilis Hantz. 7. Nitzschia palea (Kütz.) W. Sm. 8. Nitzschia paleaceae Grun. 9. Chlorella vulgaris Beij. 10. Desmodesmus communis (Hegew.) Hegew. 11. Desmodesmus intermedius (R. Chodat) Hegew. 12. Desmodesmus protuberans (Fristch \& Rich) Hegew. 13. Monoraphidium contortum (Thur.) Kom.-Legn. 14. Monoraphidium griffithi (Berk.) Kom.-Legn. 15. Monoraphidium irregulare (G. M. Smith) Kom.-Legn. 16. Monoraphidium komarkovae Nyg. Escalas $=5 \mu \mathrm{m}$ (figuras $4 \mathrm{e}$ 9); $10 \mu \mathrm{m}$ (figuras 2-3, $5-8,10-16)$.

rios do delta do Jacuí, é rica e diversificada. Os altos valores de riqueza podem ser explicados pela existência in loco de condições físicas (tempo de residência, temperatura, luz) e químicas (nutrientes) favoráveis ao desenvolvimento do fitoplâncton, bem como pela presença de banhados e áreas úmidas da planície de inundação do delta do Jacuí. Esses ambientes são considerados como fontes de inóculos de organismos, contribuindo para a manutenção da alta riqueza do fitoplâncton. Este fato pode ser confirmado por Allan (1995) ao mencionar que a presença de lagos, represas e áreas úmidas associados aos rios, são de grande importância para enriquecê-los com organismos planctônicos. Ainda, de acordo com Petts (1994) e Thomaz et al. (1997), nos rios de planícies de inundação, há maior diversidade de hábitats, fontes de alimentos e adaptações tróficas que propiciam a manutenção de uma considerável biodiversidade. Para
Bittencourt-Oliveira (2002), corpos d'água marginais, que suprem o ecossistema lótico em função do regime hidrológico, podem ser responsáveis pela origem de muitas espécies encontradas no plâncton de rios.

As classes Chlorophyceae e/ou Bacillariophyceae, que predominaram em número de táxons na foz dos rios do delta do Jacuí, também o foram na composição de diversos rios de regiões temperadas como os rios Sacramento (Greenberg 1964), Nilo (Talling \& Rzóska 1967), Thames (Lack 1971), Mississipi (Baker \& Baker 1979), St. Lawrence (Hudon et al. 1996), Mamoré (Gutiérrez \& Cadima 2004); subtropicais, rio Tibagi (Bittencourt-Oliveira 1997), rio Baía (Train \& Rodrigues 1998), rio Paraná (Schiaffino 1977; Train \& Rodrigues 1997; Train et al. 2000), rio do Prata (Goméz \& Bauer 2000), rio Juramento (Salusso \& Moraña 2000), rio Pirapó (Borges et al. 2003) e tropicais, rio Orinoco (Lewis 1988), rio Parnaíba (Câmara et al. 2002), rio Bonny (Chindah \& Braide 2004).

Em relação à sazonalidade determinada pelo clima subtropical da região de estudo, a riqueza das Chlorophyceae foi favorecida pelas temperaturas mais elevadas $\left(19\right.$ a $\left.27^{\circ} \mathrm{C}\right)$ das estações de primavera e verão e, a das Bacillariophyceae pelas temperaturas
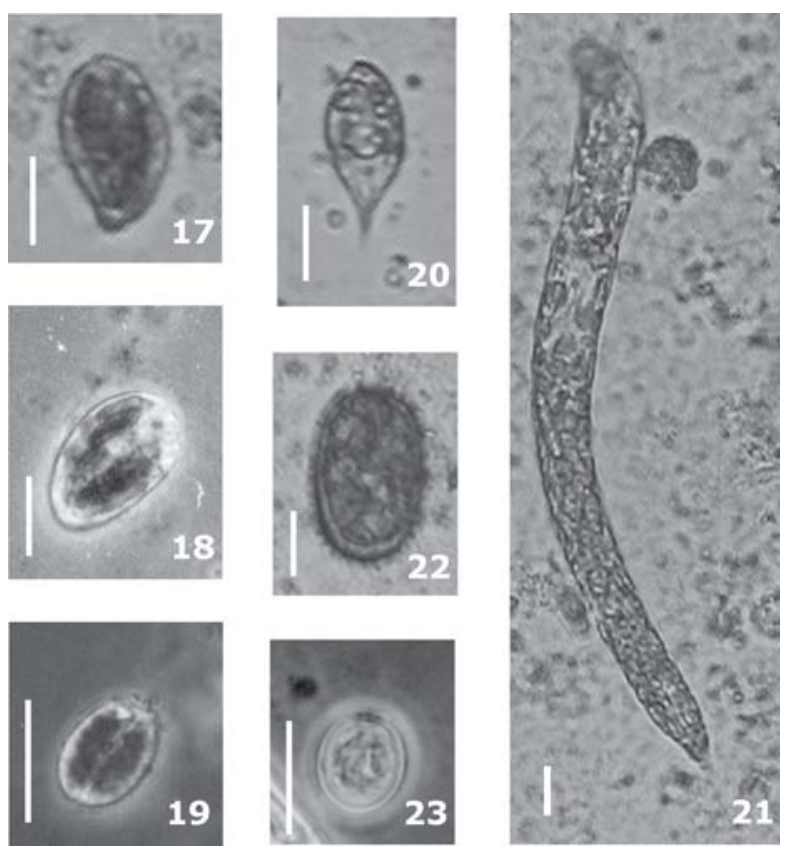

Figuras 17-23. 17. Cryptomonas marssonii Skuja. 18. Cryptomonas ovata Ehr. 19. Cryptomonas phaseolus Skuja. 20. Euglena sp. 1. 21. Euglena deses Ehr. 22. Trachelomonas hispida (Perty) Stein. 23. Trachelomonas cf. oblonga Lemm. Escalas $=10 \mu \mathrm{m}$ 

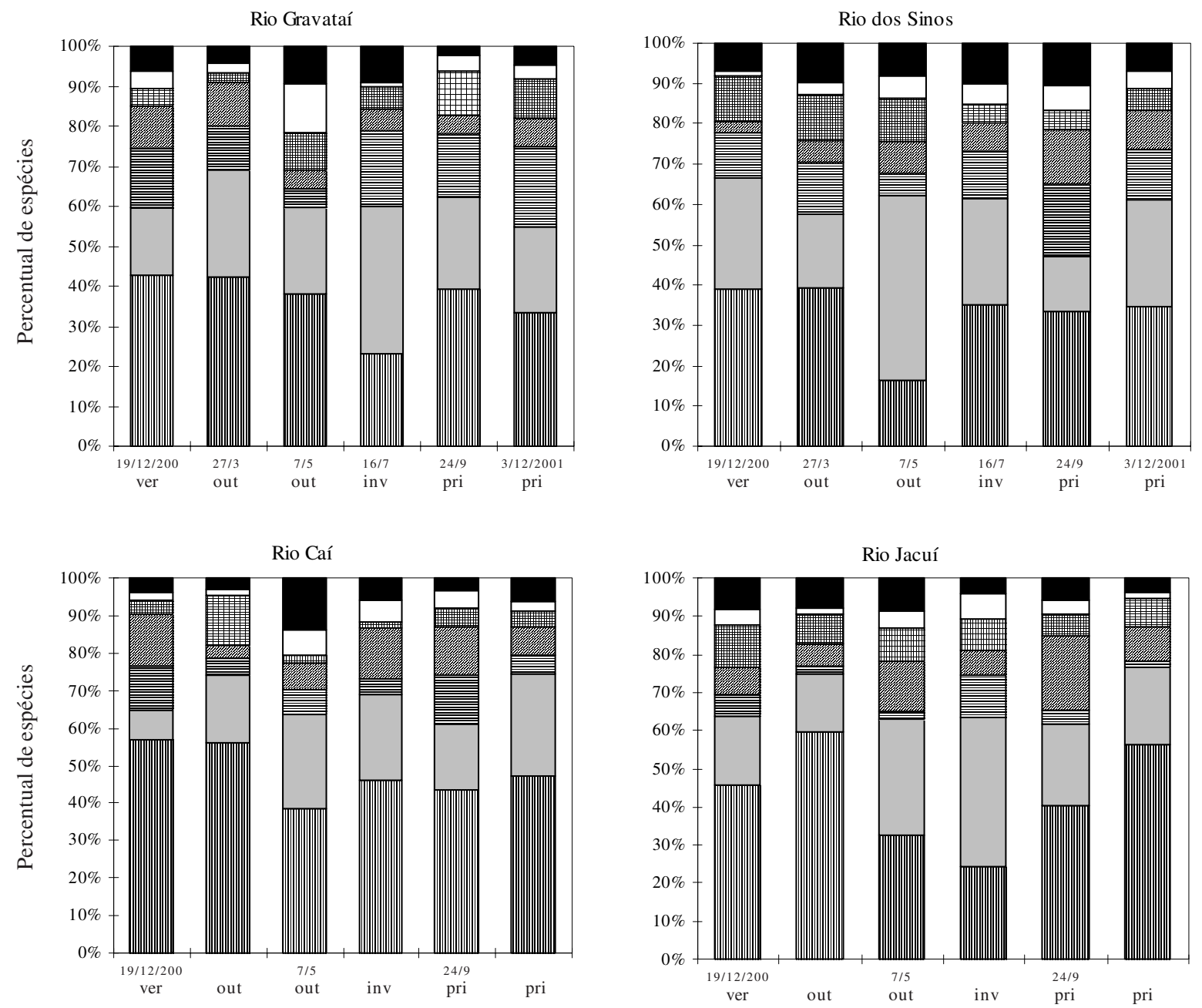

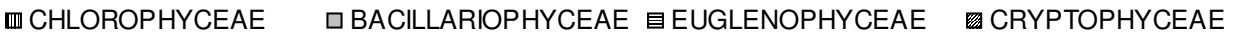 $\square$ CYANOPHYCEAE $\square$ CHRYSOPHYCEAE IOUTROS GRUPOS}

Figura 24. Variação sazonal da contribuição relativa ( $\mathrm{n}^{\circ}$ de espécies) das diferentes classes fitoplanctônicas na foz dos rios formadores do delta do Jacuí, RS, Brasil. (ver= verão; out= outono; inv= inverno; pri= primavera)

mais baixas $\left(13\right.$ a $\left.18{ }^{\circ} \mathrm{C}\right)$ do outono e inverno. Bittencourt-Oliveira (1997), em estudos do fitoplâncton no rio Tibagi, também constatou maior riqueza das Chlorophyceae no verão.

Os principais fatores determinantes da variação da riqueza na foz dos rios do delta do Jacuí foram a temperatura e o nível fluviométrico. Em geral, o aumento da riqueza esteve associado aos menores níveis da água (média de $170 \mathrm{~mm}$ ) e às temperaturas mais elevadas (média de $23,7^{\circ} \mathrm{C}$ ), registrados principalmente no verão e na primavera e, a diminuição, aos períodos de águas altas (média de $292 \mathrm{~mm}$ ) observados no outono e/ou inverno. Train \& Rodrigues

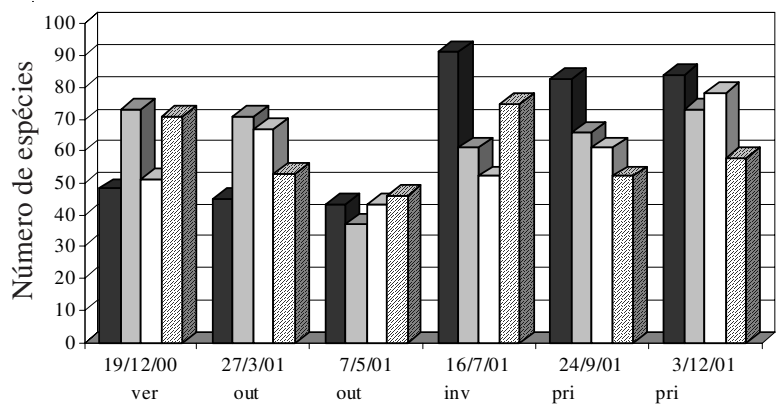

Figura 25. Variação sazonal da riqueza específica do fitoplâncton na foz dos rios formadores do delta do Jacuí, RS, Brasil (ver $=$ verão $;$ out $=$ outono $;$ inv $=$ inverno; pri $=$ primavera . घ = Gravataí; $\square=$ Sinos; $\square=$ Caí; $\mathbb{Z}=$ Jacuí). 


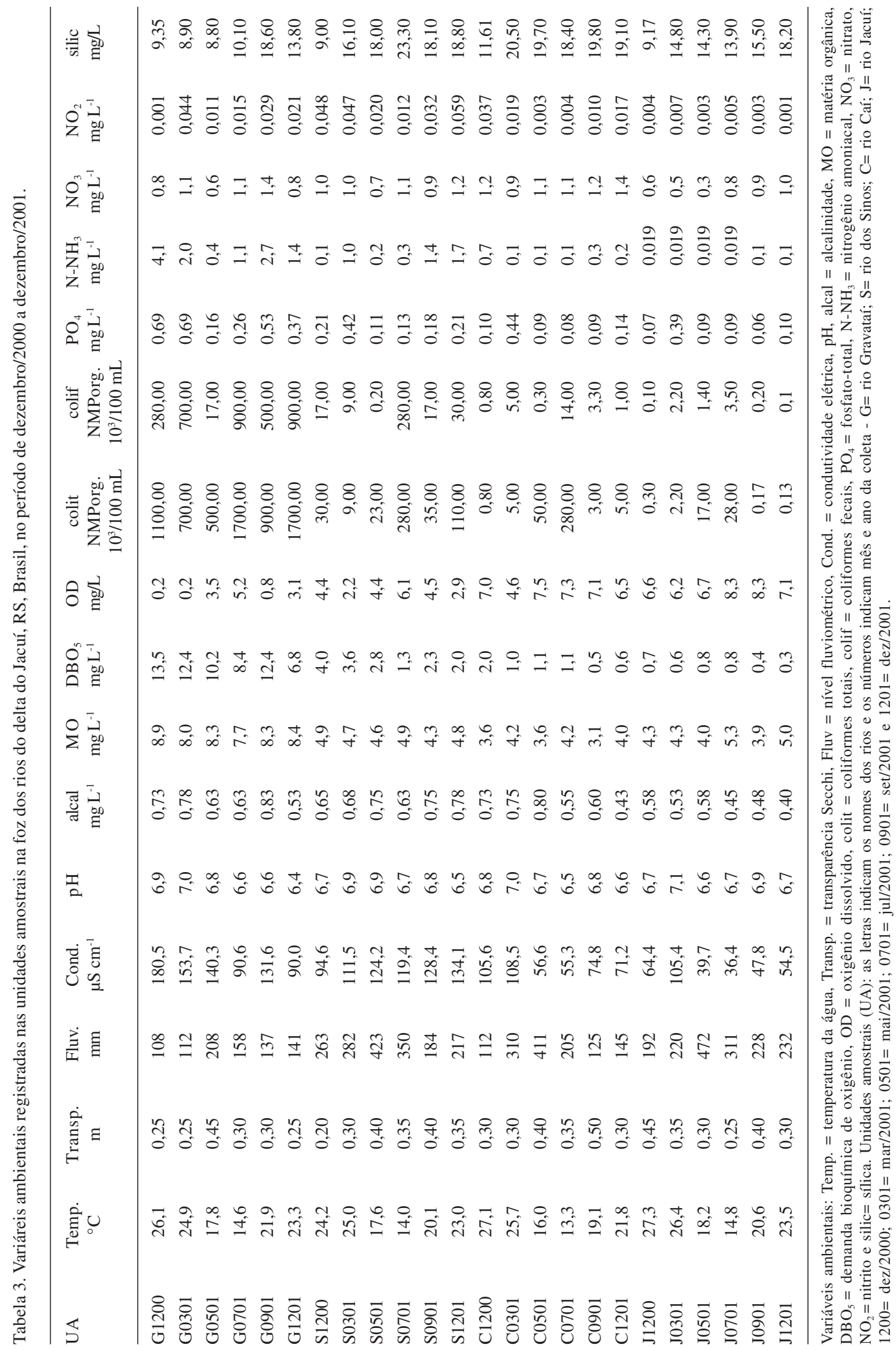




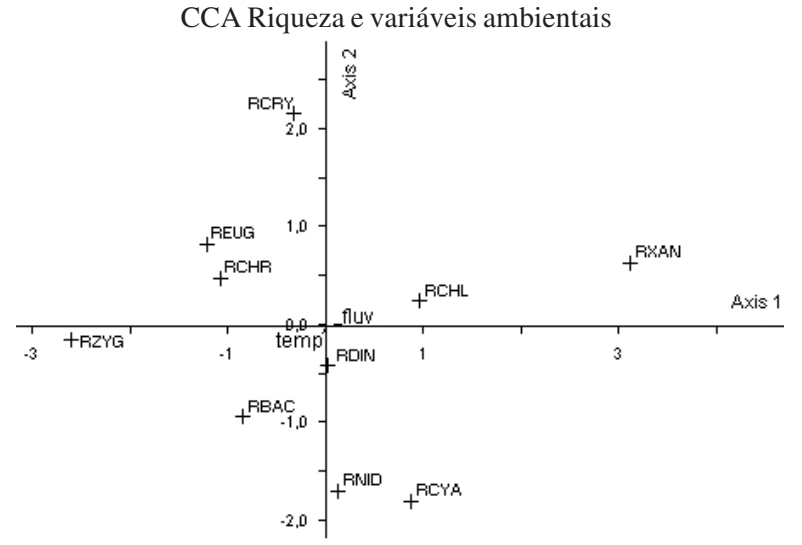

Figura 26. Diagrama de ordenação ACC para a riqueza específica das classes fitoplanctônicas $(\mathrm{R}=$ riqueza; $\mathrm{BAC}=$ Bacillariophyceae $; \mathrm{CHL}=$ Chlorophyceae $; \mathrm{CHR}=$ Chrysophyceae; $\mathrm{CRY}=$ Cryptophyceae $; \mathrm{CYA}=$ Cyanophyceae DIN = Dinophyceae; $E U G=$ Euglenophyceae; Xan = Xanthophyceae; ZIG = Zignematophyceae; NID= não identicada), em função das variáveis ambientais: temperatura (temp), nível fluviométrico (fluv), fosfato-total $\left(\mathrm{PO}_{4}\right)$, nitrogênio amoniacal $\left(\mathrm{N}-\mathrm{NH}_{3}\right)$, nitrato $\left(\mathrm{NO}_{3}\right)$, nitrito $\left(\mathrm{NO}_{2}\right)$ e sílica (silic), registradas nas 24 unidades amostrais na foz dos rios formadores do delta do Jacuí, RS, Brasil, no período de dezembro/2000 a dezembro/2001.

(1997), em análise dos estudos da comunidade fitoplanctônica realizados na planície de inundação do alto rio Paraná, nos anos de 1992 a 1994, também constataram registros de maior riqueza específica do fitoplâncton nos períodos de águas baixas e de menor riqueza nos períodos de águas altas. Gutiérrez \& Cadima (2004) observaram a ocorrência deste mesmo padrão de comportamento para a riqueza fitoplanctônica, em estudo realizado nos períodos de águas baixas e altas, em 1998, nas lagoas da planície de inundação do rio Mamoré Central (Bolívia). Por outro lado, Bittencourt-Oliveira (2002), em estudo no rio Tibagi, no Paraná, constatou aumento da riqueza da comunidade fitoplanctônica em épocas chuvosas, correspondentes à primavera (novembro/1990) e ao verão (fevereiro/1991), como consequiência da maior concentração de nutrientes oriundos do ambiente terrestre e das várzeas.

A variação sazonal da riqueza foi mais distinta nos rios Gravataí e Jacuí em comparação aos rios Caí e Sinos, fato que pode estar associado à diferença entre eles quanto à hidrometria (largura, profundidade, vazão, etc.), contribuição alóctone de organismos de seus ecossistemas associados e ao grau de eutrofização. O rio Gravataí é um rio de planície, com baixa vazão (média de $28 \mathrm{~m}^{3} / \mathrm{s}$ ) e sua bacia de 2.750 $\mathrm{km}^{2}$ possui um maior impacto antrópico devido à ocupação urbana e industrial (Porto Alegre - DMAE 1985). O aumento da riqueza no rio Gravataí, no inverno e primavera, foi constatado após a ocorrência de seu mais elevado nível da água (208 mm) e maior transparência do período $(0,45 \mathrm{~m})$, ou seja, quando o rio recebeu maior contribuição de organismos planctônicos de seus banhados associados e maior incidência de radição solar. O rio Jacuí também sofre impactos urbanos e industriais em sua bacia de 71.600 $\mathrm{km}^{2}$, mas trata-se de um rio de grande caudal (média de $888 \mathrm{~m}^{3} / \mathrm{s}$ ). rio Jacuí também foi registrado um pico de riqueza no inverno, após a maior elevação do nível da água $(472 \mathrm{~mm})$ ocorrida no outono. Porém, ao contrário do rio Gravataí, a riqueza não se manteve elevada na primavera, pois a alta vazão do rio Jacuí não permitiu um maior estabelecimento da comunidade fitoplanctônica alóctone. O outro pico ocorrido no verão pode ser explicado tanto pela diminuição do nível da água (192 mm), como por outras condições favoráveis ao desenvolvimento do fitoplâncton (luz, temperatura, etc.) presentes no período. Já os rios Sinos e Caí apresentam menor diferença quanto às dimensões de suas bacias (áreas de 3.820 e $4.980 \mathrm{~km}^{2}$ ) e às vazões (médias de $55 \mathrm{e}$ $79 \mathrm{~m}^{3} / \mathrm{s}$ ), refletindo em uma variação sazonal da riqueza específica mais semelhante entre eles. A diferença de variação da riqueza fitoplanctônica associada à hidrometria, observada nos rios Gravataí e Jacuí, pode ser comparada à observada por Train \& Rodrigues (1998) nos subsistemas rio Baía e rio Paraná da planície de inundação do alto rio Paraná.

Em síntese, os resultados demonstraram que a temperatura e o nível fluviométrico foram os principais fatores determinantes da variação sazonal da composição e riqueza da comunidade fitoplanctônica na foz dos rios do delta do Jacuí, para o período de dezembro/2000 a dezembro/2001.

\section{Agradecimentos}

Os autores são gratos a todos que contribuíram para a realização deste trabalho, em especial ao químico Manoel Luis Nunes, pelas análises químicas e à bióloga Luciana de Souza Cardoso, pelo auxílio nas análises estatísticas; à Secção de Criptógamas do Museu de Ciências Naturais da Fundação Zoobotânica do Rio Grande do Sul e ao Laboratório de Limnologia do Departamento de Ecologia da Universidade Federal do Rio Grande do Sul, pelo apoio técnico e material; à FAPERGS, pelo auxílio financeiro ao projeto. 


\section{Referências bibliograficas}

Allan, J.D. 1995. Stream Ecology: Structure and function of running waters. Nettherlands, Kluwer Academic Plublishers.

Alves-da-Silva, S.M. \& Avila, I.R. 1997. Levantamento florístico das Euglenaceae pigmentadas do Parque Estadual Delta do Jacuí, Rio Grande do Sul, Brasil. Iheringia, Série Botânica 48: 85-102.

American Public Health Association (APHA). 1992. Standart method for the examination of water and wastewater. 18 ed. Washington, American Public Health Association.

Baker, A.L. \& Baker, K.K. 1979. Effects of temperature and current discharge on the concentration and photosynthetic activity of the phytoplankton in the upper Mississippi River. Freshwater Biology 9: 191-198.

Bicudo, C.E.M.; Bicudo, D.C.; Castro, A.A.J. \& PicelliVicentim, M.M. 1992. Fitoplâncton do trecho a represar do rio Paranapanema (Usina Hidrelétrica de Rosana), Estado de São Paulo, Brasil. Revista Brasileira de Biologia 52: 293-310.

Bittencourt-Oliveira, M.C. 1993a. Ficoflórula do rio Tibagi, estado do Paraná, Brasil.: I. Desmídeas, filamentosas e gêneros Gonatozygon, Penium, Pleurotaenium e Tetmemorus (Zygnemaphyceae). Semina, Ciências Biológicas e da Saúde 14: 61-73.

Bittencourt-Oliveira, M.C. 1993b. Ficoflórula do rio Tibagi, estado do Paraná, Brasil.: III. Actinotaenium, Cosmarium e Staurodesmus (Zygnemaphyceae). Semina, Ciências Biológicas e da Saúde 14: 86-95.

Bittencourt-Oliveira, M.C. 1997. Fitoplâncton do rio Tibagi, estado do Paraná, Brasil.: Nostocophyceae, Chlorophyceae, Euglenophyceae, Chrysophyceae, e Tribophyceae. Hoehnea 24: 1-20.

Bittencourt-Oliveira, M.C. 2002. A comunidade fitoplanctônica do rio Tibagi: uma abordagem preliminar de sua diversidade. Pp. 373-402. In: M.M. Medri; E. Bianchini; O.A. Shibatta \& J.A. Pimenta (orgs.). A bacia do rio Tibagi. Londrina, FUEL.

Bittencourt-Oliveira, M.C. \& Castro, A.A.J. 1993. Ficoflórula do rio Tibagi, estado do Paraná, Brasil.: III. Gênero Closterium (Zygnemaphyceae). Semina, Ciências Biológicas e da Saúde 14: 74-85.

Bittencourt-Oliveira, M.C. \& Mecenas, P.R. 1994. Ficoflórula do rio Tibagi, estado do Paraná, Brasil.: IV. Staurastrum, Micrasterias e Xanthidium (Zygnemaphyceae). Semina, Ciências Biológicas e da Saúde 15: 133-152.

Borges, P.A.F.; Rodrigues, C.L.; Pagioro, T.A. \& Train, S. 2003. Spatial variation of phytoplankton and some abiotic variables in the Pirapó River - PR (Brazil) in August 1999: a preliminary study. Acta Scientiarium 25: 1-8.

Câmara, F.M.M.; Moura, A.N. \& Bittencourt-Oliveira, M.C. 2002. Ficoflórula palnctônica do rio Parnaíba, estado do Piauí-Brasil. Revista Nordestina de Biologia 16: 3-21.

Chindah, A.C. \& Braide, S.A. 2004. The physicochemical quality and phytoplankton community of tropical waters: a case of 4 biotopes in the lower Bonny river, Niger delta, Nigeria. Caderno de Pesquisa Série Biológica 6: 7-35.
Dickie, G. 1881. Notes on the algae from the Amazons and its tributaries. Journal Limnology Society, Series Botany 18: 123-132.

Drouet, F. 1938. The brazilian Myxophyceae 2. American Journal Botany 25: 657-666.

Fortes, D.F.; Torgan, L.C. \& Silva Júnior, A. 2003. Composição e variação sazonal do fitoplâncton (Chlorophyta - Chlorococcales s. 1.) próximo à foz do rio dos Sinos, em área pertencente ao Parque Estadual Delta do Jacuí, Rio Grande do Sul, Brasil. Iheringia, Série Botânica 58: 103-129.

Goméz, N. \& Bauer, D.E. 2000. Diversidad fitoplanctonica em la franja costera sur del rio de la Plata. Biología Acuática 19: 7-26.

Greenberg, A.E. 1964. Plankton of the Sacramento River. Ecology 45: 40-49.

Gutiérrez, M. \& Cadima, M. 2004. Fitoplancton del Río Mamoré Central. Pp. 237-257. In: M. Pouilly; S.G. Beck M.R. Moraes \& C. Ibañez (eds.). Diversidade biológica en la llanura de inundación del Rio Mamoré. Patiño, Fundação Simón I.

Hoeck, V. den C.; Mann, D.G. \& Jahns, H.M. 1995. Algae: An introduction to phycology. Cambridge, Cambridge University.

Hudon, C.; Paquet, S. \& Jarry, V. 1996. Downstream variations of phytoplankton in the St.Lawrence River (Québec, Canada). Hydrobiologia 337: 11-26.

Lack, T.J. 1971. Quantitative studies on the phytoplankton of the Rivers Thames and Kennet at Reading. Freshwater Biology 1: 213-224.

Lewis, W.M. 1988. Primary production in the Orinoco River. Ecology 69: 679-692.

Martau, L.; Aguiar, L. \& Callegaro, V.L.M. 1977. Diatomáceas do Rio dos Sinos, Rio Grande do Sul, Brasil. Iheringia, Série Botânica 22: 45-83.

Möbius, M. 1892. Über einige brasilianische algen. Bericht der deutschen botanischen gesellschaft 10: 17-26.

Musarra, M.L.; Monteiro, A.J.; Beyruth, Z. Novelli, J.L. \& Viana, N.C. 1998. Limnological characterization of lentic and lotic habitats of the Upper Paraná River system prior to the inundation of Porto Primavera Reservoir. Verhandlunger der Internationale Vereinigung Limnologie 26: 1072-1079.

Oliveira, M.D. \& Calijuri, M.C. 1995. Structure of the phytoplanktonic community in the Lobo Reservoir (SP); a comparison among the different compartiments of the reservoir: rivers, transition areas and reservoir. Anais da Academia Brasileira de Ciências 67: 369-379.

Petts, G.E. 1994. Rivers: Dynamic Components of Catchment Ecosystems. Pp. 3-22. In: Calow \& G.E. Petts (eds.). The River Handbook: hydrological and ecological principles. v. II. Oxford, Blackwell Scientific Publications.

Porto Alegre - DMAE, Prefeitura Municipal. 1985. Bacia Hidrográfica do Jacuí - Diagnóstico Hidrossanitário. Porto Alegre, DMAE.

Rolla, M.E.; Dabés, M.B.G.S.; França, R. \& Ferreira, E.M.V.M. 1992. Inventário limnológico do Rio Grande na área de influência da futura usina hidrelétrica (UHE) de Garipava. Acta Limnologica Brasiliensia 4: 139-162. 
Rosa, Z.M.; Torgan, L.C.; Lobo, E.A. \& Herzog, L.A.W. 1988. Análise da estrutura de comunidades fitoplanctônicas e de alguns fatores abióticos em trecho do Rio Jacuí, Rio Grande do Sul, Brasil. Acta Botanica Brasilica 2: 31-46.

Round, F.E. 1983. Biologia das Algas. 2 ed. Rio de Janeiro, Guanabara Dois.

Salusso, M.M. \& Moraña, L.N. 2000. Características físicas, químicas y fitoplancton de ríos y embalses de la alta cuenca del Rio Juramento (Salta, Argentina). Natura Neotropicalis 31: 29-44.

Santos, M.J. \& Rocha, O. 1998. Plankton community structure and its relation to water quality in streams under urban impacts. Verhandlunger der Internationale Vereinigung Limnologie 26: 1266-1270.

Schiaffino, M. 1977. Fitoplancton del rio Parana. i. sus variaciones en relacion al ciclo hidrologico en cauces secundarios de la llanura aluvial. Physis, Sección B 36: 115-125.

Schmidt, G.W. \& Uherkovich, G. 1973. Zur Artenfülle des Phytoplanktons in Amazonien. Amazoniana 4: 243-252.

Sournia, A. (ed.). 1978. Phytoplankton Manual. Paris, UNESCO (United Nations Educational, Scientific and Cultural Organization) (Monographs on oceanographie methodology, 6).

Souza, D. 1998. The Lobo river basin and reservoir: ecological bases for regional planning, management and conservation. Verhandlunger der Internationale Vereinigung Limnologie 26: 1281-1283.

Talling, J.F. \& Rzóska, J. 1967. The development of plankton in relation to hydrological regime in the Blue Nile. Journal Ecology 55: 637-662.
Thomasson, K. 1971. Amazonian algae. Mémoires de l'Institute Royal des Sciences Naturelles de Bélgique, 86: $1-57$.

Thomaz, S.M.; Roberto, M.C. \& Bini, L.M. 1997. Caracterização limnológica dos ambientes aquáticos e influência dos níveis fluviométricos. Pp. 73-102. In: A.E.A.M. Vazzoler; A.A. Agostinho \& N.S. Hahn (eds.). A planície de inundação do alto rio Paraná: aspectos físicos, biológicos e socioeconômicos. Maringá, EDUEM.

Torgan, L.C.; Menegheti, J.O. \& Silva, S.M.A. 1979. Contribuição ao estudo do fitoplâncton do Rio Caí, Rio Grande do Sul, Brasil. Pp. 141-150. In: Anais XXX Congresso Nacional de Botânica, São Paulo.

Train, S. \& Rodrigues, L.C. 1997. Distribuição espaçotemporal da comunidade fitoplanctônica. Pp. 105-116. In: A.E.A.M. Vazzoler; A.A. Agostinho \& N.S. Hahn (eds.). A planície de inundação do alto rio Paraná: aspectos físicos, biológicos e socioeconômicos. Maringá, EDUEM.

Train, S. \& Rodrigues, L.C. 1998. Temporal fluctuations of the phytoplankton community of the Baía river in the upper Paraná river floodplain, Mato Grosso do Sul, Brazil. Hydrobiologia 361: 125-134.

Train, S.; Oliveira, M.D. \& Quevedo, M.T. 2000. Dinâmica sazonal da comunidade fitoplanctônica de um canal lateral (canal Cortado) do alto rio Paraná. Acta Scientiarium 22: 389-399.

Uherkovich, G. 1976. Algen aus den Flüssen Rio Negro und Rio Tapajós. Amazoniana 5: 465-515.

Uherkovich, G. 1981. Algen aus einigen Gewässern Amazoniens. Amazoniana 7: 191-219.

Uherkovich, G. \& Rai, H. 1979. Algen aus den Rio Negro und seinen Nebenflüssen. Amazoniana 6: 611-638. 